\title{
Partial self-fertilization and inbreeding depression in two populations of Mimulus guttatus
}

\author{
JOHN H. WILLIS* \\ Department of Ecology and Evolution, The University of Chicago, Chicago, IL 60637, U.S.A.
}

\begin{abstract}
Inbreeding depression is likely to be a common selective force opposing the automatic selective advantage of self-fertilization in self-compatible plants and animals, yet relatively few studies have measured both the breeding system and inbreeding depression in natural populations. In this study, I estimated the frequency of selfing, using data obtained by gel electrophoresis, in two annual populations of the monkeyflower Mimulus guttatus for 2 years, and measured the relative performance of selfed and outcrossed progeny over several stages of the life cycle in both the field and the greenhouse. Rates of outcrossing were not significantly different from 1.0 in either population in 1989, but both populations exhibited significant and moderate amounts of selfing in 1990. Outcrossing rates were significantly different between years for the Cone Peak population but not for the Iron Mountain population. Significant inbreeding depression was detected for almost every component of fitness measured, including germination success, survival to flowering, and flower, fruit and seed production in the native field environments for both populations. The final cumulative value of inbreeding depression, calculated as one minus the relative total seed production of selfed to outcrossed progeny, was 0.69 for Iron Mountain and 0.64 for Cone Peak. Inbreeding depression was also severe in the greenhouse experiments, even though fitness components only up to flower production were measured: 0.52 for Iron Mountain and 0.48 for Cone Peak. These results are consistent with theoretical predictions of the magnitude of inbreeding depression in primarily outcrossing populations, and indicate that inbreeding depression is an important factor in the maintenance of outcrossing in these populations.
\end{abstract}

Keywords: breeding system, fitness component, inbreeding, inbreeding depression, Mimulus, selffertilization.

\section{Introduction}

In self-compatible hermaphroditic populations, there is an automatic transmission advantage to a mutation which acts only to increase the rate of self-fertilization. Such a gene is expected to spread to fixation in the absence of counteracting selective forces (Fisher, 1941). Selfing may also have advantages over outcrossing if it maintains local adaptation (Stebbins, 1950; Stebbins, 1957; Antonovics, 1968; Schemske, 1984), is energetically more efficient (Darwin, 1877; Schemske, 1978; Waller, 1979), or assures reproductive success when access to mates or outcrossed pollen is limited (Baker, 1955). In spite of these potentially strong selective forces favouring the evolution of self-

*Present address: Department of Biology, University of Oregon, Eugene, OR 97403, U.S.A. fertilization, animals and flowering plants often have complex adaptations which promote outcrossing (Darwin, 1862, 1877). In an attempt to resolve this apparent evolutionary paradox, many different ecological and genetic factors have been proposed that could prevent the evolution of self-fertilization.

Inbreeding depression, defined as the lowered fitness of inbred individuals compared to outcrossed individuals, can directly oppose the intrinsic selective advantage of increased selfing (Maynard Smith, 1977; Charlesworth \& Charlesworth, 1979; Lloyd, 1979; Charlesworth, 1980; Feldman \& Christiansen, 1984; Lande \& Schemske, 1985; Campbell, 1986; Holsinger, 1988; Charlesworth, Morgan \& Charlesworth, 1990). While ecological and other genetic factors have clearly played very important roles in the evolution of breeding systems, inbreeding depression may be a universal selective factor opposing the evolution of selfing in 
organisms with a prolonged diploid phase of the life cycle, because it is likely to exist in populations which vary widely in their natural history. Universality arises because all organisms are subject to mutation to deleterious alleles, the vast majority of which are at least slightly recessive, and this component of genetic load is thought to be the major cause of inbreeding depression in natural populations (Simmons \& Crow, 1977; Crow \& Simmons, 1983; Charlesworth \& Charlesworth, 1987).

Theoretical models that consider the evolution of self-fertilization in the presence of inbreeding depression often predict that selection will favour either complete outcrossing or complete selfing (Maynard Smith, 1978; Lloyd, 1979; Charlesworth, 1980; Feldman \& Christiansen, 1984; Lande \& Schemske, 1985; Charlesworth, Morgan \& Charlesworth, 1990). This prediction is supported by evidence that selfing rates in natural plant populations are approximately bimodally distributed (Schemske \& Lande, 1985; Barrett \& Eckert, 1990; Soltis \& Soltis, 1992; but see Aide, 1986; Waller, 1986). When selfed pollen competes with outcrossed pollen to fertilize ovules and when the ability of selfing genotypes to contribute to the outcrossing pollen pool is unaffected, these models predict that selection favours self-fertilization only if inbreeding depression, calculated as one minus the relative fitness of selfed to outcrossed progeny, is less than one-half. Campbell (1986) and Holsinger (1988) have claimed that inbreeding depression, as a population parameter, has little predictive value in mating system evolution. This claim has not been supported by the results of recent models that allow for the joint evolution of inbreeding depression and of selfing rate modifiers with small effects, which generally show that inbreeding depression greater than one-half will prevent the evolution of increased selfing (Lande \& Schemske, 1985; Charlesworth \& Charlesworth, 1987; Ziehe \& Roberds, 1989; Charlesworth \& Charlesworth, 1990; Charlesworth, Morgan \& Charlesworth, 1990; Charlesworth et al. 1991).

The magnitude of inbreeding depression in natural populations is expected to evolve with the mating system. If mutational load is the principal cause of inbreeding depression, then inbred populations are expected to have lower inbreeding depression than historically outcrossed populations, due to the increased efficiency of selection against recessives in inbred populations (Lande \& Schemske, 1985; Charlesworth \& Charlesworth, 1987; Charlesworth, Morgan \& Charlesworth, 1990; Charlesworth et al., 1991). Studies of inbreeding depression in natural populations often find that inbreeding depression is substantial, even in highly selfing populations (reviewed in Lande \& Schemske, 1985; Charlesworth
\& Charlesworth, 1987; Charlesworth, Charlesworth \& Morgan, 1990), although the magnitude of inbreeding depression often depends on which fitness components are measured (e.g. Price \& Waser, 1979; Schemske, 1983; Schoen, 1983; Schemske \& Pautler, 1984; Karron, 1989; Levin, 1989; Dudash, 1990; Holtsford \& Ellstrand, 1990; Johnston, 1992) and on whether the experiments were conducted in the field or in more controlled greenhouse environments (Schemske, 1983; Dudash, 1990; Schmitt \& Ehrhardt, 1990; Schmitt \& Gamble, 1990).

Although knowledge of the relationship between outcrossing rate and inbreeding depression is clearly important for an understanding of selective factors involved in mating system evolution, relatively few empirical studies have measured both the breeding system and magnitude of inbreeding depression in natural populations (Schoen, 1983; Charlesworth \& Charlesworth, 1987; Kohn, 1988; Stevens \& Bougourd, 1988; Dudash, 1990; Holtsford \& Ellstrand, 1990; Ritland, 1990a; Dole \& Ritland, 1993). The purpose of this study is to estimate the frequency of self-fertilization, and to determine the magnitude of inbreeding depression, for several major components of fitness in two populations of the monkeyflower Mimulus guttatus (Scrophulariaceae). In order to determine the effect of the environment on the expression of genetic load, the inbreeding depression experiments were conducted in the native field environments and in more controlled greenhouse conditions.

\section{Materials and methods}

\section{Study species and populations}

$M$. guttatus $(2 n=28)$ is a self-compatible wildflower that lives throughout western North America. It is found from Alaska to Mexico and as far east as the Rockies, usually inhabiting moist areas such as stream banks, roadsides, or wet meadows. Populations may be either annual or perennial, depending on the seasonal availability of moisture. It is especially convenient for genetic studies because of its short generation time ( $\mathrm{ca}$. 2-3 months), lack of seed dormancy, many seeds (at least several dozen) per fruit, and ease of emasculation and hand pollination. M. guttatus is reported to exhibit interpopulational variability in outcrossing rates (Ritland, 1990a; Ritland \& Ganders, 1987a) and inbreeding depression (Ritland \& Ganders, 1987b; Ritland, 1990a).

I studied two annual populations of $M$. guttatus in Oregon's Western Cascades. The populations are situated on the exposed, seasonally moist slopes of two adjacent mountains, Iron Mountain and Cone Peak, 
which are separated by about 1 mile. Although the Iron Mountain and Cone Peak populations exist in relatively small areas of localized seepage from melting snow (less than $400 \mathrm{~m}^{2}$ ), both populations consist of tens of thousands of individuals. The plants germinate in early June shortly after snow melt, flower in late June and early July, and set seed by late July. All plants die by the end of July as a result of normally low summer rainfall. Previous studies of these populations have revealed substantial inbreeding depression due to chlorophyll-deficient lethals (Willis, 1992).

\section{Estimation of outcrossing rates}

Outcrossing rates in both populations were estimated in 1989 and 1990 using data obtained by gel electrophoresis of progeny arrays. Maternal families of seeds were sampled in both years by collecting whole plants in the field in early August, after seeds had ripened. About 30 families from each population were sampled along $10 \mathrm{~m}$ transects with sampling points spaced about $20 \mathrm{~cm}$ apart. Plants nearest to each point and bearing at least 15 seeds were harvested until at least 30 families were collected. As some plants bore fewer than 15 seeds, this method of sampling, though necessary for adequate family sizes, is biased toward collecting large individuals.

Seeds from all fruits on a given plant were combined and between 15 and 20 seeds per family were planted in the greenhouse at the University of Chicago. Seeds were germinated on a mist bench under natural light, typically resulting in high rates of germination (75-85 per cent). Up to 12 seedlings per family (depending on family size and germination rate) were transplanted individually into flats and induced to flower under high intensity sodium lights and long (16 h) days. Less than 5 per cent of these seedlings failed to flower. Tissue homogenate was obtained by grinding fresh corolla tissue in extraction buffer. This homogenate was absorbed onto filter paper wicks and frozen at $-70^{\circ} \mathrm{C}$ until use. The multilocus genotypes of progeny were scored for up to three polymorphic enzyme systems: aconitase (ACO), 6-phosphogluconate dehydrogenase (6PGD, 2 loci), and phosphoglucomutase (PGM). In 1989, using a morpholine citrate buffer ( $\mathrm{pH} 6.1$; Clayton \& Tretiak, 1972), reliable expression was only obtained for ACO and 6PGD-1. In 1990, I achieved reliable expression for 6PGD-2 and PGM with a Triscitrate buffer ( $\mathrm{pH}$ 6.3/6.7; Selander et al., 1971). However, only the Cone Peak population is polymorphic for these two additional loci. All loci were determined to be inherited in a Mendelian fashion by inspection of families and by reference to previous studies (McClure, 1973; Ritland \& Ganders, 1987a).
Data were analysed using the maximum-likelihood multi-locus outcrossing procedure described in Ritland \& Jain (Ritland \& Jain, 1981; Ritland, 1990b), which provides estimates of the multi-locus outcrossing rate, the mean single-locus outcrossing rate, the inbreeding coefficient of the maternal parents, and the gene frequencies in the pollen and ovule pools. Standard errors of these estimates were based on 1000 bootstrapped estimates, with the progeny array being the unit of resampling (Ritland, 1990b).

\section{Inbreeding depression studies}

Parents used in these experiments were collected as seeds from each population in August 1989 by sampling approximately 350 seed families along a $1 \times 15 \mathrm{~m}$ grid with sampling points spaced $20 \mathrm{~cm}$ apart. As before, plants nearest to each point on the grid and bearing at least 15 seeds were collected. Seeds from each of these families were germinated in the University of Chicago's greenhouse in the late fall of 1989 and one seedling from each family was randomly selected to be used in the crosses. Seedlings were transplanted into $9 \mathrm{~cm}$ square pots and induced to flower as described above. In the winter of 1990, flowering plants from the same population were arranged into pairs at random. Hand pollinations were then conducted on these pairs such that each parent in a pair was self-pollinated and outcrossed reciprocally to the other parent in the pair. Four different crosses were therefore performed in a diallel fashion on each of the roughly 150 pairs of plants (referred to hereafter as diallels) per population: the two self-pollinations and the two reciprocal outcrosses. This crossing design is a powerful method for detecting inbreeding depression because it eliminates the contribution of parental sampling and maternal effects to the standard error of the difference between the means of selfed and outcrossed individuals (Lynch, 1988).

In late May 1990, up to 20 seeds per family (mean seed number per family $=18.9$ ) were counted and planted in 98-cell flats filled with ProMix. All seeds from a particular family were planted in the same cell and families within populations were assigned randomly to cells. Flats were placed on the mist bench at the University of Chicago for several days and were then transported within 4 days to the greenhouse at the University of Oregon in Eugene, Oregon. Most seeds had germinated by the end of the trip in early June and 3 days later, all families were censused for the number of germinated seeds. One hundred diallels from each population were then randomly selected from those diallels with at least two seedlings from each of the four crosses. Two seedlings from each of these 400 families 
per population were then randomly selected and transplanted into either the greenhouse array or the field, as described below. Each family was therefore represented by a single seedling in both the greenhouse and field experiments.

For the field experiment, seedlings were transplanted 2-3 days after the census into their original population in a $5 \times 80$ grid, with points separated by 20 $\mathrm{cm}$. Seedlings were planted directly into the native vegetation with minimal disturbance and were marked with numbered 'flags' made of bamboo skewers and coloured labelling tape. Transplanted seedlings were censused every other day for survival and flowering. All plants were dead by the end of July and were then harvested. Care was taken to harvest plants as seeds became ripe, so that seeds would not be lost. Fortunately, all plants could be harvested at roughly the same time because plants produced few fruits and died due to drought within days of each other. Harvested plants were censused for total number of flowers, fruits, and seeds produced.

For the greenhouse experiment, seedlings were transplanted on days 4 and 5 after the census date into 60 -cell flats filled with a standard greenhouse potting soil (each cell approx. $4.5 \mathrm{~cm}$ square) in a chequerboard pattern such that every other cell was empty. Seedlings within a population were planted in a completely random design, while plants from different populations were planted in separate arrays. To facilitate bottom watering, the flats were then placed inside four galvanized steel basins ( $1 \mathrm{~m} \times 4 \mathrm{~m}$ by $0.1 \mathrm{~m}$ deep). The two basins for each population were placed immediately adjacent to each other, but because of limited space, basins for different populations were placed about $10 \mathrm{~m}$ apart. Notice that this design is not strictly a common garden design, as the two groups of basins (and hence populations) might have experienced different environmental conditions. As the purpose of both the greenhouse and field experiments was to measure inbreeding depression within populations, this design is not a problem. Plants were watered daily by bottom watering and censused every other day for survival and flowering. Daily watering was stopped on 21 July, approximately 8 weeks after the seeds were planted. Plants were censused one last time for survival to flowering and total flower production on 25 July, after all plants had died. Fruit and seed production was not monitored because the plants were never observed to be visited by pollinators, and fruit and seed set was very low.

All fitness components except per cent germination were analysed separately for the field and greenhouse experiments. The performance of selfed and outcrossed progeny was analysed in two ways. First, differences between the two treatments were tested with data from all individuals. For example, the mean number of seeds was calculated by including all individuals in the analysis, even those that had died before flowering. In these tests, the means for outcrossed and selfed progeny were calculated separately for each diallel and then tested for a significant difference using paired $t$-tests. The paired $t$-tests were computed as described by Lynch (1988, and personal communication) using the equation $t=\Delta \bar{z} /\left(V_{0} / L\right)^{1 / 2}$, where $\Delta \bar{z}$ is the mean difference between outcrossed and selfed progeny, $V_{0}$ is the phenotypic variance of the outcrossed progeny, and $L$ is the number of diallels. As $L=100$ in these experiments, there are 99 d.f.

The tests described above were computed by including all individuals in the analyses, regardless of whether they survived to flowering. In order to determine the relative contribution of different components of fitness to the total inbreeding depression, the measured traits were transformed into conditional or independent fitness components. These multiplicative fitness components, calculated separately for each cross (family), were: (i) the proportion of seeds that germinated; (ii) the chance, 0 or 1 , that a germinated seed flowered; (iii) the number of flowers per plant, given that the plant had flowered; (iv) the number of fruits per flower on plants that produced one or more flowers; and $(\mathrm{v})$ the number of seeds per fruit, given that one or more fruits were produced. Because these conditional fitness components were calculated from only a subset of the original plants used in the experiments, these traits could not be analysed using the paired $t$-tests described above. Instead, they were analysed using unpaired $t$-tests with the family structure ignored.

In order to see how inbreeding depression accumulates over the life cycle of Mimulus, the expected fitness of a particular cross (family) at any stage in the life cycle was calculated simply by multiplication of the independent fitness components up to that life history stage. The average fitness of outcrossed and selfed individuals in a particular experiment was calculated up to each stage of the life cycle and inbreeding depression was calculated as $\left[1-\left(\bar{w}_{\mathrm{s}} / \bar{w}_{\mathrm{o}}\right)\right]$, where $\bar{w}_{\mathrm{s}}$ and $\bar{w}_{\mathrm{o}}$ are the mean fitnesses of selfed and outcrossed progeny, respectively.

\section{Results}

\section{Outcrossing rates}

Both Iron Mountain and Cone Peak were predominantly outcrossing in 1989 and exhibited significant 
Table 1 Outcrossing rates $(t)$ and their standard errors for Iron Mountain and Cone Peak. The standard errors are based on 1000 bootstraps

\begin{tabular}{lccccc}
\hline & \multicolumn{3}{c}{ Iron Mountain } & & \multicolumn{2}{c}{ Cone Peak } \\
\cline { 2 - 3 } \cline { 6 - 6 } & 1989 & 1990 & & 1989 & 1990 \\
\hline Number of families & 30 & 24 & & 29 & 25 \\
Number of progeny & 342 & 221 & & 297 & 281 \\
Multi-locus $t$ & $0.91(0.07)$ & $0.76(0.11)^{*}$ & & $1.03(0.06)$ & $0.66(0.10)^{*}$ \\
Mean single locus $t$ & $0.91(0.08)$ & $0.71(0.12)^{*}$ & & $1.01(0.06)$ & $0.61(0.11)^{*}$ \\
Ave. Diff. & $0.01(0.03)$ & $0.05(0.04)$ & & $0.01(0.04)$ & $0.05(0.02)^{*}$ \\
$F$ & $0.05(0.16)$ & $0.06(0.23)$ & & $0.10(0.12)$ & $-0.30(0.08)$ \\
ACO only & $0.98(0.10)$ & $0.65(0.19)$ & & $0.99(0.07)$ & $0.49(0.13)^{*}$ \\
6PGD-1 only & $0.79(0.11)$ & $0.77(0.22)$ & & $1.05(0.13)$ & $0.72(0.19)$ \\
6PGD-2 only & - & - & & - & $0.88(0.20)$ \\
PGM only & - & - & & - & $0.62(0.21)$ \\
\hline
\end{tabular}

$* P<0.05$.

amounts of selfing in 1990 (Table 1). Multi-locus and mean single-locus outcrossing rates in 1989 were not significantly different from 1.0 in both populations. The average difference between the multi-locus and single-locus rates, based on 1000 bootstraps, was not significantly different from zero, suggesting that biparental inbreeding was absent or infrequent (Ritland, 1990b). Average inbreeding coefficients of the inferred maternal genotypes were low and not significantly different from zero. In 1990, both populations had outcrossing rates that were significantly different from 1.0. The estimated multi-locus outcrossing rate was 0.76 for Iron Mountain and 0.66 for Cone Peak. Inspection of the standard errors of these estimates reveals a significant difference between 1989 and 1990 for Cone Peak, but not for Iron Mountain (Table 1).

\section{Inbreeding depression}

Seeds produced by self-fertilization were significantly less likely to germinate than seeds produced by outcrossing in both populations (Table 2). This difference resulted in inbreeding depression values at this early stage of the life cycle of about 10 per cent for both populations. This is shown graphically in Fig. 1.

For all four fitness components measured in the field, selfed progeny had significantly lower values than outcrossed progeny, in both populations (Table 2). Selfed seedlings were much less likely than outcrossed seedlings to flower in the Iron Mountain population, where only 35.5 per cent of all seedlings survived to flowering. Pre-flowering mortality was much less in the Cone Peak population ( 70.3 per cent of all seedlings flowered), and inbreeding depression for this fitness component was less than that for the Iron Mountain population. Cumulative inbreeding depression values incorporating probabilities of germination and flowering reflect this difference between the populations: inbreeding depression already exceeded 0.5 for Iron Mountain, while inbreeding depression was only 0.2 at this stage for Cone Peak (Fig. 1). Selfed progeny produced significantly fewer flowers than outcrossed progeny in both populations (Table 2). The multiplicative fitness component number of flowers per flowering plant, as with the other previously discussed multiplicative fitness components, was significantly different between the two types of progeny in both populations. Inbreeding depression at this stage increased to 0.63 for Iron Mountain and to 0.42 for Cone Peak (Fig. 1). The extreme difference between selfed and outcrossed progeny remained significant for total fruit and seed production in both populations; however, only the Cone Peak population showed a significant difference between the progeny types for the conditional fitness components fruits per flower and seeds per fruit (Table 2 ). This could reflect a real difference between the populations, but statistical power was quite low on Iron Mountain as only 44 outcrossed and 17 selfed seedlings out of 200 of each class set seed, compared with 123 and 85, respectively, on Cone Peak. Whatever the cause of the difference, cumulative inbreeding depression did not change much as the final two multiplicative components of fitness were incorporated into the estimate for Iron Mountain, while inbreeding depression steadily increased for Cone Peak. The final values of cumulative inbreeding depression were almost identical for the two populations: Iron Mountain was 0.69 and Cone Peak was 0.65 (Fig. 1). 
Table 2 Performance of outcrossed and selfed progeny. The data are presented in two ways: either as the means and standard errors of all planted individuals or as the means and standard errors of conditional fitness components. Values for all individuals are calculated from the means of the 100 diallels, and the statistical tests are presented are paired $t$-tests. Values for the conditional fitness components are calculated from all individuals, ignoring family structure, and the statistical tests for these traits are unpaired $t$-tests. See text for further explanation

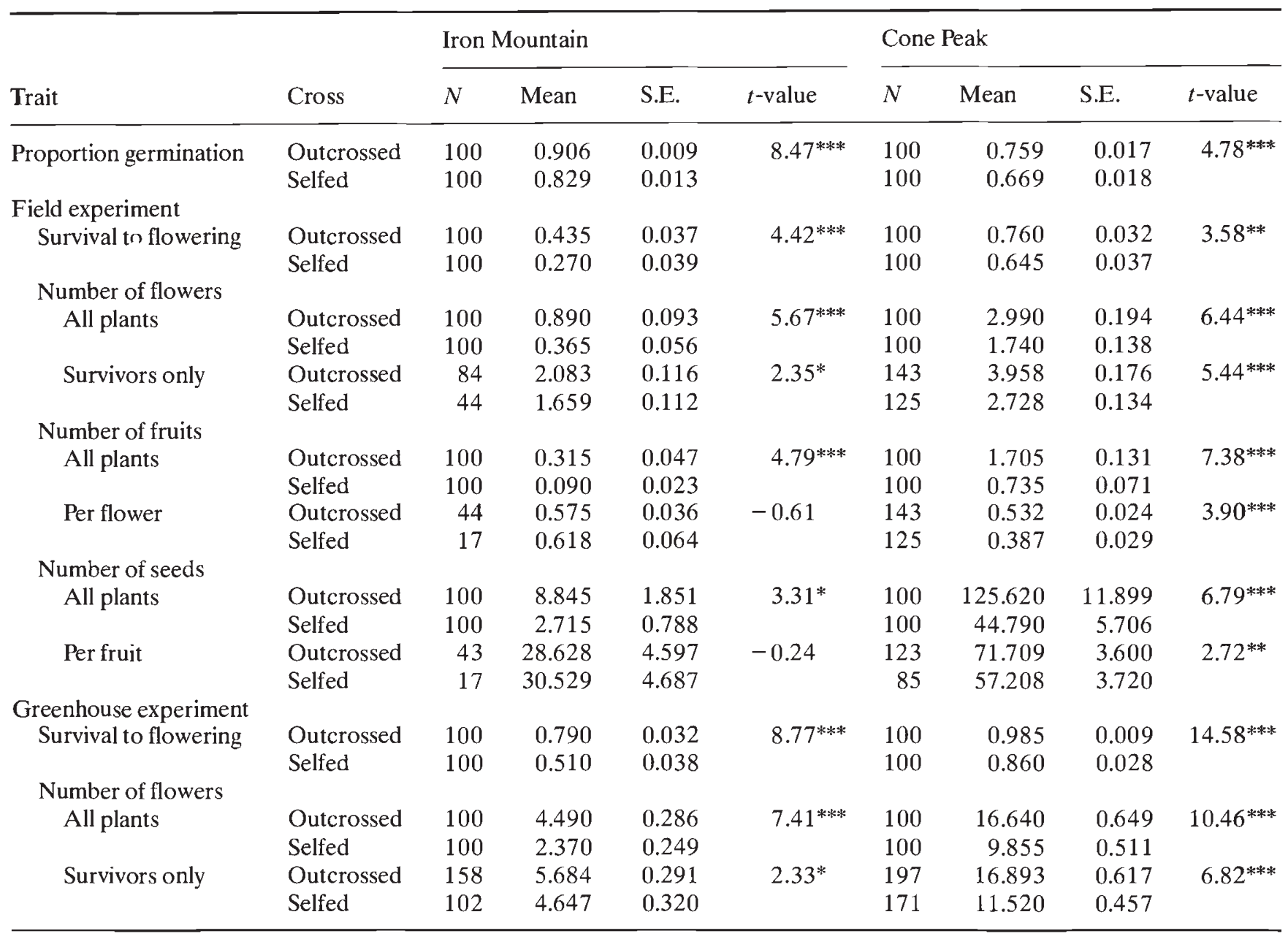

${ }^{*} P<0.05 ;{ }^{* *} P<0.01 ; * * * P<0.001$.

As with the field experiments, selfed progeny performed significantly worse than outcrossed progeny in the greenhouse for the fitness traits measured (Table 2). Fewer plants from Iron Mountain flowered than plants from Cone Peak and cumulative inbreeding depression up to this stage was greater for Iron Mountain (0.42) than for Cone Peak (0.22). Inbreeding depression at this stage increased for both populations over that caused purely by germination rate differences (Fig. 2). Total number of flowers differed significantly between selfed and outcrossed individuals in both populations (Table 2), as did the multiplicative fitness component number of flowers per flowering plant (Fig. 2). The final measures of inbreeding depression, up to number of flowers produced, were quite similar for Iron Mountain (0.52) and Cone Peak (0.48).

\section{Discussion}

Outcrossing rates for both Iron Mountain and Cone Peak were not significantly different from 1.0 in 1989 , but were significantly lower than this in 1990 . The outcrossing rates were significantly different between the 2 years for Cone Peak, but not for Iron Mountain. The outcrossing rates measured in this study are typical of, or slightly higher, than those found in studies of other annual and perennial $M$. guttatus populations in California, Washington, and British Columbia (Ritland \& Ganders, 1987a; Ritland, 1989, 1990a; Dole \& Ritland, 1993). Most of the populations in these studies were found to have roughly intermediate outcrossing rates, with estimates ranging from 25 to 80 per cent. Yearly variation in selfing rates has also been docu- 


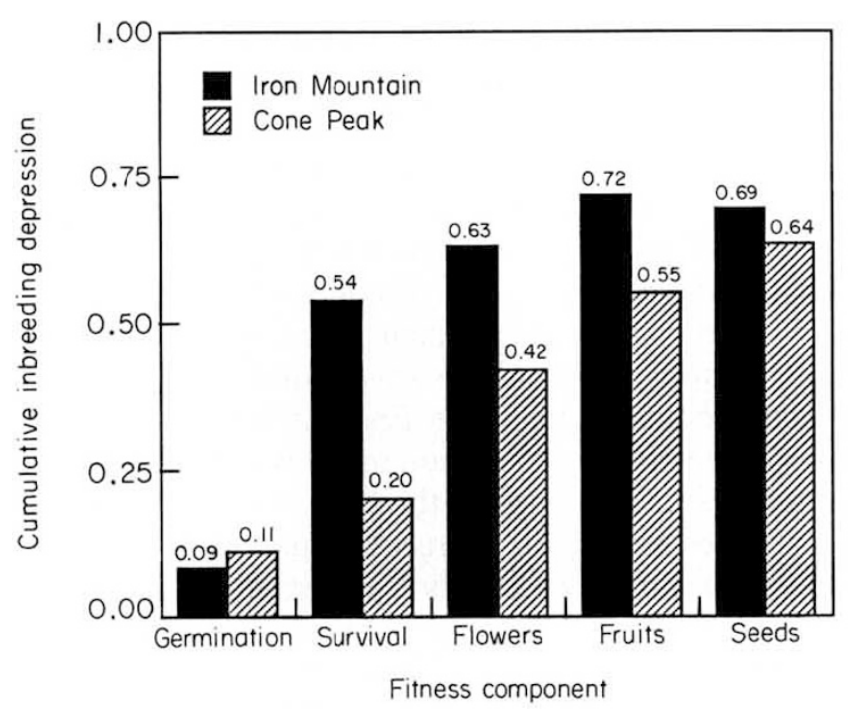

Fig. 1 Cumulative inbreeding depression in the field. Inbreeding depression up to a particular conditional or multiplicative fitness component is calculated as $\left[1-w_{\mathrm{s}} / w_{0}\right]$.

mented for a $M$. guttatus population in California (Dole \& Ritland, 1993). The cause of the increased levels of selfing observed for the Cone Peak population in 1990 is not known. M. guttatus is usually pollinated by Bombus species and Apis mellifera (Harris, 1979; Macnair et al., 1989) and it is possible that pollinators were particularly scarce in 1990 . M. guttatus is known to practise delayed selfing in the absence of pollinators when the corolla, which is attached to the anthers, is shed several days after anthesis (Dole, 1990). Alternatively, variable environmental factors could have directly influenced the plants' propensity to selfpollinate, perhaps by causing changes in floral traits thought to affect selfing rates, like stigma-anther separation and stigmatic sensitivity (Macnair \& Cumbes, 1989; Ritland \& Ritland, 1989).

Regardless of the mechanisms responsible for the significant levels of selfing in 1990; it is clear that the populations examined in this study are mainly, but not entirely, outcrossing. Theoretical studies of partially selfing populations generally predict that equilibrium levels of inbreeding depression due to mutation-selection balance will be greater than 0.5 for such populations, and will decline as selfing rates increase (Lande \& Schemske, 1985; Campbell, 1986; Charlesworth \& Charlesworth, 1987; Charlesworth, Morgan \& Charlesworth, 1990; Charlesworth et al., 1991). Although inbreeding depression caused by heterozygote advantage can increase with the selfing rate (Charlesworth \& Charlesworth, 1987; Ziehe \& Roberds, 1989; Charlesworth \& Charlesworth, 1990), overdominance does not seem to be a major component of genetic load (Simmons and Crow, 1977; Crow \& Simmons, 1983; Sprague, 1983; Charlesworth

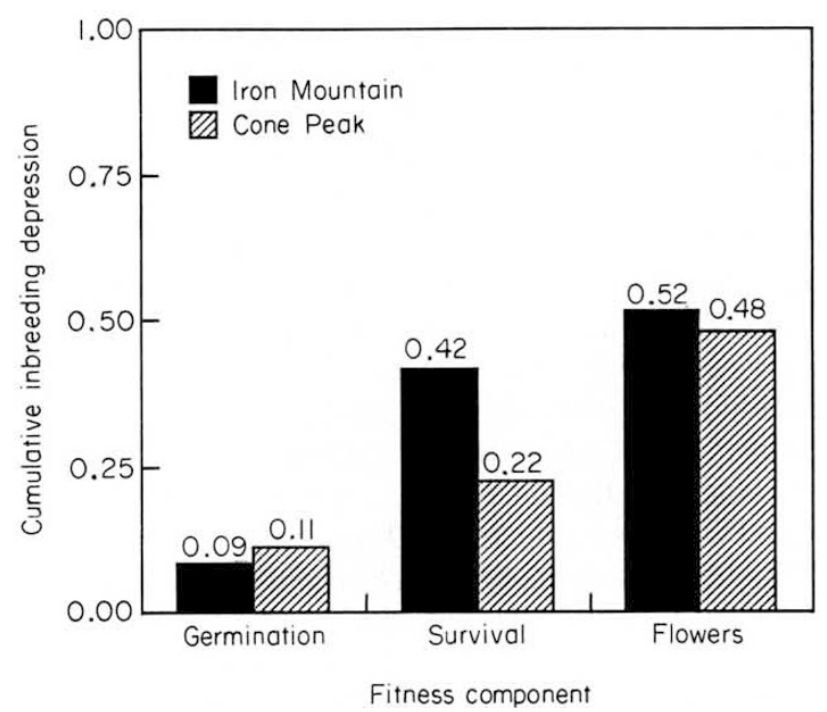

Fig. 2 Cumulative inbreeding depression in the greenhouse. Inbreeding depression up to a particular conditional or multiplicative fitness component is calculated as $\left[1-w_{\mathrm{s}} / w_{\mathrm{o}}\right]$.

\& Charlesworth, 1987). In this study, inbreeding depression values exceeded the critical value of 0.5 predicted by theory to maintain the evolutionary stability of outcrossing in the field experiments for Iron Mountain (0.69) and Cone Peak (0.64). Inbreeding depression measured in the greenhouse, based on fitness components up to the stage of flower production only, approached 0.5 (Iron Mountain, 0.52; Cone Peak, 0.48 ). In both populations, inbreeding depression was manifest at almost all measured stages of the life cycle. Clearly, these estimates of inbreeding depression are in agreement with the qualitative theoretical predictions of mutation-selection balance.

Inbreeding depression could have been underestimated in this study because it was not possible to measure every component of fitness and plants could not be monitored throughout their life in a totally natural environment. For example, seed set resulting from the selfed and outcrossed pollinations was not measured in this study. Inbreeding depression acting at this early stage, caused by differential fertilization and/ or seed abortion, has been detected in many studies (Jain, 1978; Price \& Waser, 1979; Schemske, 1983; Schemske \& Pautler, 1984; Levin, 1989, 1991; Kohn, 1988; Stevens \& Bougourd, 1988; Dudash, 1990; Manasse \& Pinney, 1991; Weller \& Ornduff, 1991) but not in other studies (Schemske, 1983; Schoen, 1983; Karron, 1989; Levin, 1989; Holtsford \& Ellstrand, 1990). Male fertility is another major fitness component that was not measured in this study. Other experiments on the effects of inbreeding in the Iron Mountain and Cone Peak populations (Willis, 1993), as well as in other M. guttatus populations (Ritland \& 
Ganders, 1987b), have demonstrated strong inbreeding depression for the proportion of viable pollen grains produced. It is likely that had male fertility been measured in this study, the magnitude of inbreeding depression would have been even greater. These considerations only serve to strengthen the conclusion that inbreeding depression is severe in these populations. In an attempt to overcome this problem of unmeasured stages in the life cycle, Ritland (1990a) estimated the magnitude of inbreeding depression in 14 other $M$. guttatus populations by examining changes in the inbreeding coefficient at electrophoretic markers. $\mathrm{He}$ found that the average inbreeding depression estimated in this way was far more severe (about 0.7 ) than he had found in previous experimental studies in a growth chamber (about 0.25; Ritland \& Ganders, 1987b), where only a couple of fitness components were measured. Unfortunately, the indirect electrophoretic method can suffer from considerable statistical uncertainty and bias, and usually cannot identify stages of life cycle during which selection occurs (Ritland, 1990a).

In this study, inbreeding depression significantly increased at every stage of the life cycle examined for Cone Peak in both the greenhouse and field. In the Iron Mountain population, all multiplicative fitness components significantly increased inbreeding depression except for fruits per flower and seeds per fruit. Several other studies have demonstrated large values of inbreeding depression in partially selfing species of flowering plants, depending on the stage of the life cycle examined and on the environment. Schemske (1983) examined inbreeding depression in three largely outcrossing species of Costus in the field and greenhouse and detected inbreeding effects on seed production following pollination and on long-term growth in the greenhouse, but no effects on seed germination or seedling establishment in either environment. Schoen (1983), in field experiments on an outcrossing population of Gilia achilleifolia, also found that most effects of inbreeding were manifest during late stages of the life cycle. Inbreeding depression in both of these studies approached 0.5. Stevens \& Bougourd (1988) observed cumulative inbreeding depression including stages up to seedling growth of about 0.7 in the greenhouse in the primarily outcrossing Allium schoenoprasum, with seed germination and seedling establishment having less effect than parental seed set and seedling growth. Dudash (1990) studied inbreeding depression in several environments, including the field, in the outcrossing Sabatia angularis and found the largest inbreeding effects during survival after rosette formation and reproduction. Greater effects of inbreeding on later stages in the life cycle also have been obtained for Clarkia tembloriensis (Holtsford \& Ellstrand, 1990).
This study did not detect substantial differences between the field and greenhouse on the expression of inbreeding depression, even though plants in the field were generally less likely to flower and had much lower flower production than plants in the greenhouse ('Table 2). Inbreeding depression in the field was about 10 per cent higher at both the probability of flowering and flower production stages than in the greenhouse for Iron Mountain, while there was no difference between the environments for Cone Peak. Statistical comparisons of inbreeding depression in the two environments is not possible because of the lack of standard errors on the estimates of inbreeding depression. Other studies have detected effects of the environment on the magnitude of inbreeding depression (Schemske, 1983; Dudash, 1990; Schmitt \& Ehrhardt, 1990; Schmitt \& Gamble, 1990). Dudash (1990), for example, found inbreeding depression to be the most severe in the native field site, compared with the garden and greenhouse environments. Schmitt and colleagues have shown that inbreeding depression is intensified by intraspecific competition in the predominantly selfing species Impatiens capensis (Schmitt \& Ehrhardt, 1990) and by increasing distance of seedling locations from their parental sites (Schmitt \& Gamble, 1990).

Here it has been demonstrated that both the Iron Mountain and Cone Peak populations are mainly but not exclusively outcrossing, and that they harbour substantial genetic load. This load is manifest as inbreeding depression for many components of fitness when plants are raised either in the native field environment or in the greenhouse. These results are consistent with the results of population genetic models which predict that inbreeding depression should exceed one-half in primarily outcrossed populations (e.g. Lande \& Schemske, 1985; Charlesworth et al., 1990), and the data suggest that genetic load in these populations continues to be a powerful selective factor in the evolutionary maintenance of outcrossing in these populations.

\section{Acknowledgements}

I am very grateful to my thesis advisors, D. Schemske and D. Charlesworth, and to the members of my Committee, S. Arnold, B. Charlesworth, R. Lande, and $M$. Wade, for many helpful suggestions during the planning stages of this study and for comments on an early version of this manuscript. I would also like to thank M. Johnston, M. Morgan, K. Karoly, J. Coyne, S. Hattingh, D. Houle, S. Barrett, M. Macnair, C. Eckert, and M. Lynch for many fruitful discussions and/or comments on an earlier version of the manuscript, $\mathrm{S}$. Willis, T. Willis, B. Brodie, and R. Lande for assistance in the field, and S. Yamins, J. Zdenek, and S. Suwanski 
for expert greenhouse care. This research was supported by grants from NSF (Dissertation Improvement Grant \# 88-05736), Sigma-Xi, and the Hinds Fund. M. Lynch kindly arranged for the greenhouse space that I used at the University of Oregon.

\section{References}

AIDE, T. M. 1986. The influence of wind and animal pollination on variation in outcrossing rates. Evolution, 40, 434-435.

ANTONOvics, J. 1968. Evolution in closely adjacent plant populations. V. Evolution of self-fertility. Heredity, 23, 219-238.

BAKER, H. G. 1955. Self-compatibility and establishment after 'long-distance' dispersal. Evolution, 11, 449-460.

BARRETT, S. C. H. AND ECKERT, C. G. 1990. Variation and evolution of mating systems in seed plants. In: S. Kawano (ed.) Biological Approaches and Evolutionary Trends in Plants. Academic Press, San Diego, CA, pp. 229-254.

CAMPBELL, R, B, 1986. The interdependence of mating structure and inbreeding depression. Theoret. Pop. Biol., 30, 232-244.

CHARLESWORTH, B. 1980. The cost of sex in relation to mating system. J. Theoret. Biol., 84, 655-671.

CHARLESWORTH, B., CHARLESWORTH, D. AND MORGAN, M. T. 1990. Genetic loads and estimates of mutation rates in highly inbred plant populations. Nature, 347, 380-382.

CHARLESWORTH, B., MORGAN, M. T. AND CHARLESWORTH, D. 1991. Multilocus models of inbreeding depression with synergistic selection and partial self-fertilization. Genet. Res., Camb., 57, 177-194.

CHARLESWORTH, D. AND CHARLESWORTH, B. 1979. The evolutionary genetics of sexual systems in flowering plants. Proc. Roy. Soc. Lond. B, 205, 513-530.

CHARLESWORTH, D. AND CHARLESWORTH, B, 1987. Inbreeding depression and its evolutionary consequences. Ann. Rev. Ecol. Syst., 18, 237-268.

CHARLESWORTH D. AND CHARLESWORTH, B. 1990. Inbreeding depression with heterozygote advantage and its effect on selection for modifiers changing the outcrossing rate. Evolution, 44, 870-888.

CHARLESWORTH, D., MORGAN, M. T. AND CHARLESWORTH, B. 1990. Inbreeding depression, genetic load and the evolution of outcrossing rates in a multi-locus system with no linkage. Evolution, 44, 1469-1489.

CLAYTON, J. W. AND TRETIAK, D. N. 1972. Amine-citrate buffers for $\mathrm{pH}$ control in starch gel electrophoresis. J. Fisheries Res. Board Can., 29, 1169-1172.

CROW, J. F. AND SIMMONS, M. J. 1983. The mutation load in Drosophila. In: Ashburner, M., Carson, H. L. and Thompson, J. N. (eds.) The Genetics and Biology of Drosophila. Academic Press, London, pp. 1-35.

DARWIN, C. R. 1862. The Various Contrivances by which Orchids are Fertilized by Insects. John Murray, London.

DARwIN, C. R. 1877. The Different Forms of Flowers on Plants of the Same Species. John Murray, London.

DolE, J. A. 1990. Role of corolla abscission in delayed selfpollination of Mimulus guttatus (Scrophulariaceae). Amer. J. Bot., 77, 1505-1507.
DOLE, J. A. AND RITLAND, K. 1993. Inbreeding depression in two Mimulus taxa measured by multigenerational changes in the inbreeding coefficient. Evolution, 47, 361-373.

DUDASH, M. R. 1990. Relative fitness of selfed and outcrossed progeny in a self-compatible, protandrous species, Sabatia angularis L. (Gentianaceae): a comparison in three environments. Evolution, 44, 1129-1139.

Feldman, M. W. AND Christiansen, F. B. 1984. Population genetic theory of the cost of inbreeding. Amer. Nat., 123, 642-653.

FISHER, R. A. 1941. Average excess and average effect of a gene substitution. Ann. Eugen., 11, 53-63.

HARRIS, J. E. 1979. The pollination ecology and sexual reproductive ecology of Mimulus guttatus along an elevational gradient. Master's Thesis, University of Utah, Salt Lake City.

HOLSINGER, K. E. 1988. Inbreeding depression doesn't matter: The genetic basis of mating system evolution. Evolution, 42, 1235-1244.

HOLSINGER, K. E. AND FELDMAN, M. W. AND CHRISTIANSEN, F. B. 1984. The evolution of self-fertilization in plants: a population genetic model. Amer. Nat., 124, 446-453.

HOLTSFORD, T. P., AND ELLSTRAND, N. C. 1990. Inbreeding effects in Clarkia tembloriensis (Onagraceae) populations with different natural outcrossing rates. Evolution, 44, 2031-2046.

JAIN, S. K. 1978. Breeding system in Limnanthes alba: several alternative measures. Amer. J. Bot., 65, 272-275.

JOHNSTON, M. O. 1992. Effects of cross and self-fertilization on progeny fitness in Lobelia cardinalis and L. siphilitica. Evolution, 46, 688-702.

KARRON, J. D. 1989. Breeding systems and levels of inbreeding depression in geographically restricted and widespread species of Astragalus (Fabaceae). Amer. J. Bot., 76, 331-340.

KOHN, J. 1988. Why be female? Nature, 335, 431-433.

LANDE, R. AND SCHEMSKE, D. w. 1985. The evolution of selffertilization and inbreeding depression in plants. I. Genetic models. Evolution, 39, 24-40.

LEVIN, D. A. 1989. Inbreeding depression in partially selffertilizing Phlox. Evolution, 43, 1417-1423.

LEVIN, D. A. 1991. The effect of inbreeding on seed survivorship in Phlox. Evolution, 45, 1047-1049.

LLOYD, D. G, 1979. Some reproductive factors affecting the selection of self-fertilization in plants. Amer. Nat., 113, 67-79.

LLOYD, D. G. 1980. Demographic factors and mating patterns in angiosperms. In: Solbrig, O. T. (ed.) Demography and Evolution in Plant Populations. Blackwell, Oxford, pp. 67-88.

LYNCH, M. 1988. Design and analysis of experiments on random genetic drift and inbreeding depression. Genetics, 120, 791-807.

MACNAIR, M. R. AND CUMBES, Q. J. 1989. The genetic architecture of interspecific variation in Mimulus. Genetics, 122, 211-222.

MACNAIR, M. R., MACNAIR, V. E. AND MARTIN, B. E. 1989. Adaptive speciation in Mimulus: an ecological comparison of $M$. cupriphilus with its presumed progenitor, M. guttatus. New Phytol., 112, 269-279. 
MANASSE, R. S. AND PINNEY, K. 1991. Limits to reproductive success in a partially self-incompatible herb: fecundity depression at serial life-cycle stages. Evolution, 45, 712-720.

MAYNARD SMITH, J. 1977. The sex habit in plants and animals. In: Christiansen, F. B. and Fenchel, T. M. (eds) Measuring Selection in Natural Populations. Springer-Verlag, Berlin, pp. 265-273.

maYnard SMITH, J. 1978. The Evolution of Sex. Cambridge University Press, Cambridge.

McClURE, s. 1973. Allozyme variability in natural populations of the yellow monkey-flower, Mimulus guttatus, located in the north Yuba River drainage. Ph. D. thesis, University of California, Berkeley.

PRICE, M. V. AND WASER, N. M. 1979. Pollen dispersal and optimal outcrossing in Delphinium nelsoni. Nature, 277, 294-297.

RITLAND, C. AND RITLAND, K. 1989. Variation of sex allocation among eight taxa of the Mimulus guttatus species complex. Amer. J. Bot., 76, 1731-1739.

RITLAND, K. 1990a. Inferences about inbreeding depression based upon changes of the inbreeding coefficient. Evolution, 44, 1230-1241.

RITLAND, K. 1990b. A series of FORTRAN computer programs for estimating plant mating systems. J. Heredity, 81, 235-237.

RITLAND, K. AND GANDERS, F. R. 1987a. Covariation of selfing rates with parental gene fixation indices within populations of Mimulus guttatus. Evolution, 41, 760-771.

RITLAND, K. AND GANDERS, F. 1987b. Crossability of Mimulus guttatus in relation to components of gene fixation. Evolution, 41, 772-786.

RITLAND, K. AND JAIN, S. K. 1981. A model for the estimation of outcrossing rate and gene frequencies using $n$ independent loci. Heredity, 47, 35-52.

SCHEMSKE, D. w. 1978. Evolution of reproductive characters in Impatiens (Balsaminaceae): the significance of cleistogamy and chasmogamy. Ecology, 59, 596-613.

SCHEMSKE, D. w. 1983. Breeding system and habitat effects on fitness in three neotropical Costus (Zingiberaceae). Evolution, 37, 523-539.

SCHEMSKE, D. W. 1984. Population structure and local selection in Impatiens pallida (Balsaminaceae), a selfing annual. Evolution, 38, 817-832.

SCHEMSKE, D. W. AND PAUTLER, L. P. 1984. The effects of pollen composition on fitness components in a neotropical herb. Oecologia (Berlin), 62, 31-36.

SCHEMSKE, D. W. AND LANDE, R. 1985. The evolution of selffertilization and inbreeding depression in plants. II. Empirical observations. Evolution, 39, 41-52.

SCHMITT, J. AND EHRHARDT, D. W. 1990. Enhancement of inbreeding depression by dominance and suppression in Impatiens capensis. Evolution, 44, 269-278.

SCHMITT, J. AND GAMBLE, S. E. 1990. The effect of distance from the parental site on offspring performance in Impatiens capensis: a test of the local adaptation hypothesis. Evolution, 44, 2022-2030.

SCHOEN, D. J. 1983. Relative fitnesses of selfed and outcrossed progeny in Gilia achilleifolia (Polemoniaceae). Evolution, 37, 292-301.

SELANDER, R. K., SMITH, M. H., YANG, S. Y., JOHNSON, W. E. AND GENTRY, J. B. 1971. Biochemical polymorphism and systematics in the genus Peromyscus. I. Variations in the old-field mouse ( $P$. polionotus). University of Texas Publishers, 103, 49-90.

SIMMONS, M. J. AND CROW, J. F. 1977. Mutations affecting fitness in Drosophila populations. Ann. Rev. Genet., 11, 49-78.

SOKAL, R. R. AND ROHLF, F. J. 1981. Biometry, 2nd ed. Freeman, New York.

SOLTIS, D. E. AND SOLTIS, P. S. 1992. The distribution of selfing rates in homosporous ferns. Amer. J. Bot., 79, 97-100.

SPRAGUE, G. F. 1983. Heterosis in maize: theory and practice. In: Frankel, R. (ed.) Heterosis: Reappraisal of Theory and Practice. Springer-Verlag, Berlin, pp. 48-70.

Stebins, G. L. 1990. Variation and Evolution in Plants. Columbia University Press, New York.

STEBBINS, G. L. 1957. Self-fertilization and population variation in the higher plants. Amer. Nat., 91, 337-354.

STEVENS, J. P. AND BOUGOURD, S. M. 1988. Inbreeding depression and the outcrossing rate in natural populations of Allium schoenoprasum L. (wild chives). Heredity, 60, 257-261.

WALLER, D. M. 1979. The relative costs of selfed and outcrossed seeds in Impatiens capensis (Balsaminaceae). Amer. J. Bot., 66, 313-320.

WALLER, D. M. 1986. Is there disruptive selection for self fertilization? Amer. Nat., 128, 421-426.

WELlER, S. G. AND ORNDUFF, R. 1991. Pollen tube growth and inbreeding depression in Amsinckia grandiflora (Boraginaceae). Amer. J. Bot., 78, 801-804.

WILLIS, J. H. 1991. The role of inbreeding depression in the evolution of two partially self-fertilizing populations of Mimulus guttatus. Ph. D. thesis, University of Chicago, IL.

wILLIS, J. H. 1992. Genetic analysis of inbreeding depression due to chlorophyll-deficient lethals in Mimulus guttatus. Heredity, 69, 562-572.

wILLIS, J. H. 1993. Effects of different levels of inbreeding on fitness components in Mimulus guttatus. Evolution, in press.

ZIEHE, M. AND ROBERDS, J. H. 1989. Inbreeding depression due to overdominance in partially self-fertilizing plant populations. Genetics, 121, 861-868. 